\title{
Associated injuries in patients with maxillofacial trauma. Analysis of 312 consecutive cases due to road traffic accidents
}

\author{
ON Obuekwe $e^{a}$ and M Etetafia ${ }^{a}$
}

\begin{abstract}
Over a six-month period, 312 consecutive patients with maxillofacial injuries due to road traffic accidents (RTAs) were studied for associated injuries. The results show that 138 patients (44.2\%) had other injuries elsewhere. The male to female ratio was 2.7:1 and males in the 21-30-year age group were most often involved. Minibus (26.2\%) was the vehicle most often involved, and tyre blowout $(21.3 \%)$ was the commonest contributory factor in RTAs. The commonest associated injury was head injury (55.8\%) and the commonest maxillofacial injuries were mandibular fractures (29.2\%) and forehead lacerations (37.3\%). Only $44.8 \%$ of the patients with maxillofacial injuries were referred to the maxillofacial surgeon. Delay in referral, from several hours to four weeks, of some patients with facial injuries to the maxillofacial surgeon was observed.
\end{abstract}

\section{INTRODUCTION}

Victims of facial injury often sustain multiple injuries to other organ systems. ${ }^{1}$ Road traffic accidents (RTAs) are responsible for most multiple injuries ${ }^{2,3}$ and the maxillofacial region is involved in a significant proportion of cases. ${ }^{4}$ Patients with dramatic facial injuries are most often assigned to a subspecialty

KeY Words: Maxillofacial trauma, injuries, road traffic accidents

${ }^{a}$ Department of Oral and Maxillofacial Surgery, University of Benin Teaching Hospital, Benin City, Edo State.

Correspondence: Obuekwe O.N., Department of Oral and Maxillofacial Surgery, University of Benin Teaching Hospital, Benin City, Edo State. service. It is therefore important for subspecialists to consider whether the patient has been evaluated for the presence of multiple injuries. ${ }^{5,6}$ Diagnostic failures are known to occur in $12 \%$ of RTA victims and $23 \%$ of motorcycle RTA victims. ${ }^{7}$ In multiple injured patients, all organ systems must be evaluated by protocol and continuously monitored throughout the initial resuscitation and operative treatment. ${ }^{1}$

The aim of this study was to determine the frequency of concomitant injuries among patients with maxillofacial trauma due to RTAs and to assess the involvement of the maxillofacial surgeon in the provision of care for these patients. 


\section{PATIENTS AND METHODS}

Over a six-month period (December 1999May 2000), 1,114 patients presenting at the Accident and Emergency Department of the University of Benin Teaching Hospital (UBTH) as a result of RTAs were retrospectively studied. Selection for the study was possession of a maxillofacial injury due to RTA. The contributory factors to RTA, use of safety devices, maxillofacial and associated injuries, period between injury and referral of patient to the maxillofacial surgeon, as well as other clinical and demographic data were collected for analysis.

\section{RESULTS}

A total of 1,114 patients with injuries due to RTAs were involved in the study, out of which $312(28.0 \%)$ sustained injuries in the maxillofacial region. The male to female ratio of patients was 2.7:1; their ages ranged from 2.5 to 80 years, while males in the 21-30-year age group were most often affected (Table 1).
Three patients $(1.0 \%)$ had their seat belts on at the time of the accident. There was no record of helmet use. Ten patients (3.2\%) died within three days of the accident. Minibus $(26.2 \%)$ was the type of vehicle most often involved in the RTAs (Figure 1) and tyre blowout (21.3\%) was the commonest contributory factor (Figure 2). One hundred and thirty patients (44.2\%) had concomitant injuries, of which head injury (55.8\%) was the most common (Table 2). Only 140 patients (44.8\%) with maxillofacial injuries were referred to the maxillofacial surgeon. The period between injury and maxillofacial consultation ranged from several hours to four weeks. Tables 3 and 4 show the distribution of maxillofacial injuries. Mandibular fractures (29.2\%) and forehead lacerations (37.3\%) were the most common. Eleven patients (12.4\%) sustained fractures of the maxilla (Table 3). Of these, 3 (3.4\%) were Le Forte I fractures, 7 (7.9\%) were Le Forte II and 1 (1.1\%) was a Le Forte III fracture.

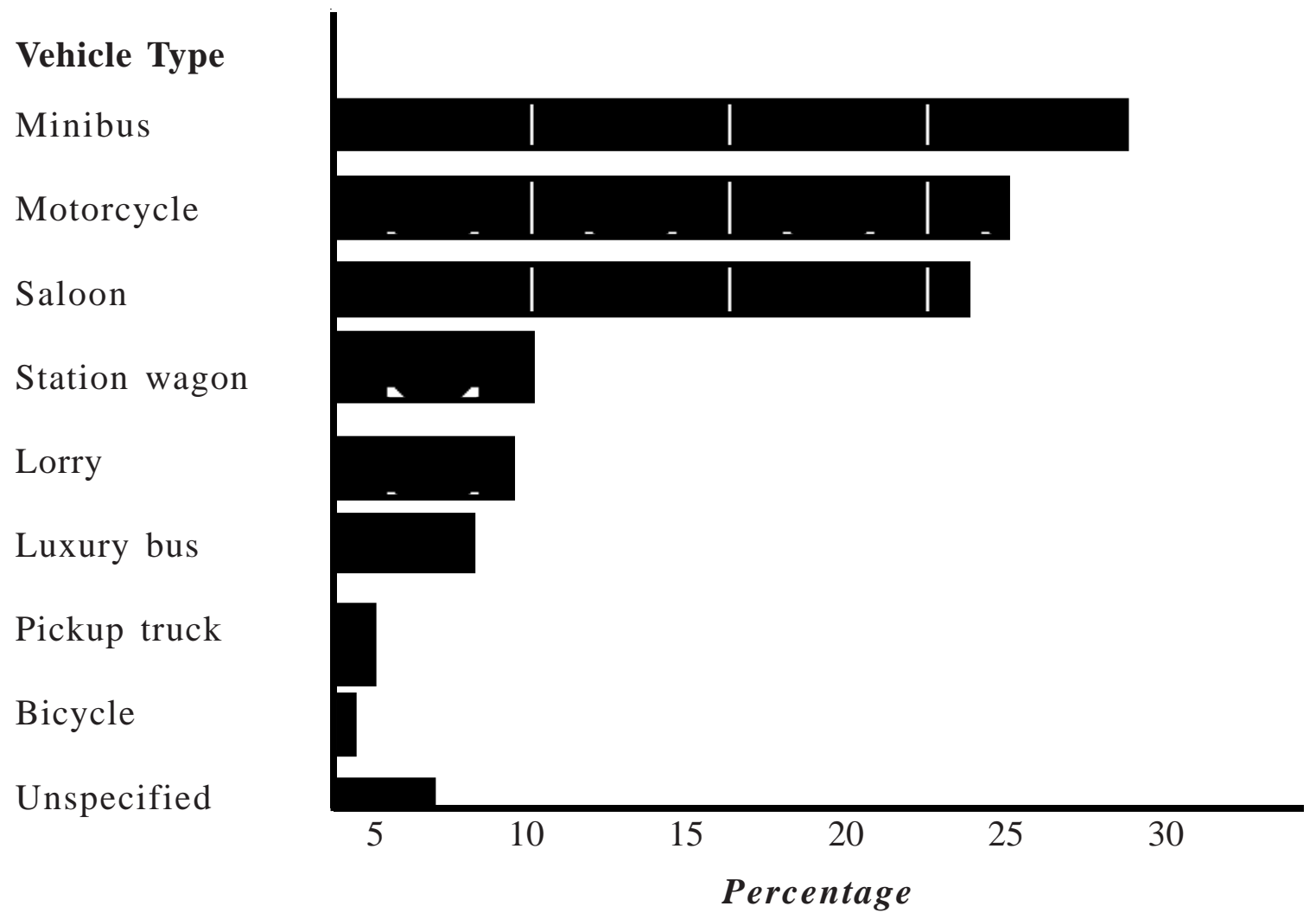

Figure 1: Distribution of patients by vehicle types 


\section{Cause}

Tyre blow-out

Loss of control

Head-on collision

Non-head-on collision

Motor car/Pedestrian

Somersault

Motorcycle/Pedestrian

Brake failure

Unspecified

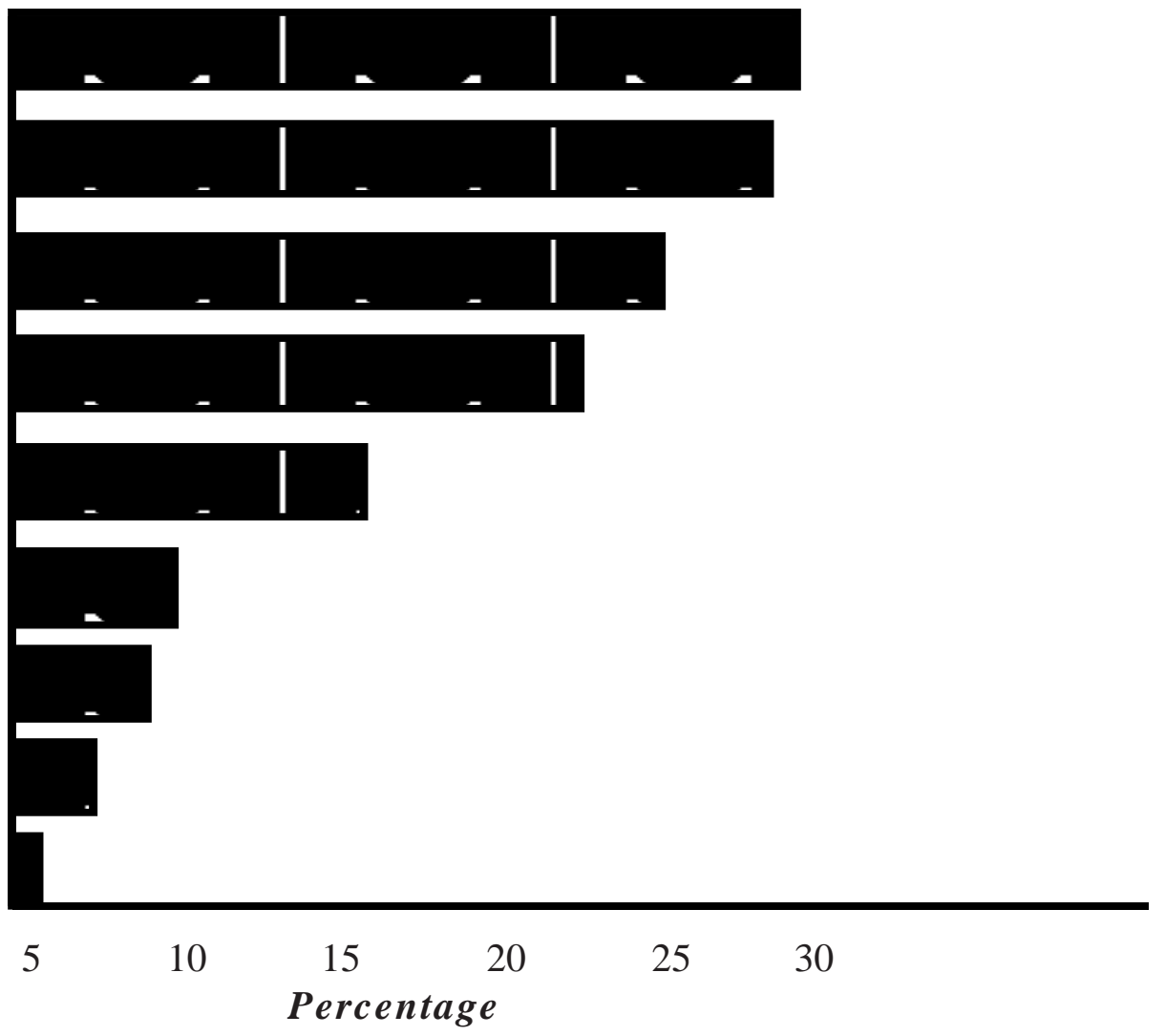

Figure 2: Aetiology of RTAs

Table $1 \quad$ Age and sex distribution of patients

\begin{tabular}{lcrrr}
\hline Age range (years) & Male & Female & $\begin{array}{r}\text { Number of } \\
\text { patients }\end{array}$ & \% \\
\hline $0-10$ & 16 & 4 & 20 & 6.4 \\
$11-20$ & 20 & 10 & 30 & 9.6 \\
$21-30$ & 85 & 32 & 117 & 37.5 \\
$31-40$ & 66 & 15 & 81 & 26.0 \\
$41-50$ & 20 & 16 & 36 & 11.5 \\
$51-60$ & 14 & 4 & 18 & 5.8 \\
$61-70$ & 4 & 2 & 6 & 1.9 \\
$71-80$ & 3 & 1 & 4 & 1.3 \\
\hline Total & $\mathbf{2 2 8}$ & $\mathbf{8 4}$ & $\mathbf{3 1 2}$ & $\mathbf{1 0 0}$ \\
\hline
\end{tabular}


Table 2

Distribution of associated injuries

\begin{tabular}{lcc}
\hline Type & No. of patients & \% \\
\hline Head injury & 77 & 55.8 \\
Fracture of the clavicle & 15 & 10.9 \\
Fracture of the femur & 13 & 9.4 \\
Fracture of the humerus & 8 & 5.8 \\
Fracture of the tibia & 6 & 4.3 \\
Fracture of the fibula & 5 & 3.6 \\
Fracture of the pelvis & 5 & 3.6 \\
Fracture of the ribs & 4 & 3.0 \\
Cervical spine injury & 2 & 1.4 \\
Ocular injury & 2 & 1.4 \\
Haemothorax & 1 & 0.8 \\
\hline Total & 138 & 100 \\
\hline
\end{tabular}

Table $3 \quad$ Distribution of facial bone fractures

\begin{tabular}{lcc}
\hline Fracture site & Number & \% of total \\
\hline Mandible & 26 & 29.2 \\
Zygomatic complex & 16 & 18.0 \\
Nasoethmoidal & 14 & 15.7 \\
Dentoalveolar & 14 & 15.7 \\
Maxilla & 11 & 12.4 \\
Orbital & 8 & 9.0 \\
\hline Total & $\mathbf{8 9}$ & $\mathbf{1 0 0}$ \\
\hline
\end{tabular}

Table 4 Distribution of soft tissue injuries

\begin{tabular}{lrr}
\hline Site & Number & \% of total \\
\hline Forehead & 126 & 37.3 \\
Scalp & 47 & 13.9 \\
Chin & 33 & 9.8 \\
Cheek & 32 & 9.5 \\
Upper lip & 29 & 8.5 \\
Temple & 29 & 8.5 \\
Lower lip & 17 & 5.0 \\
External nose & 9 & 2.7 \\
Upper eyelid & 9 & 2.7 \\
Tongue & 4 & 1.2 \\
Oral mucosa & 2 & 0.6 \\
Soft palate & 1 & 0.3 \\
\hline Total & $\mathbf{3 3 8}$ & $\mathbf{1 0 0}$ \\
\hline
\end{tabular}

26 patients sustained injuries at more than one anatomical site.

(C) CMS UNIBEN JMBR 2004; 3(1): 30-36 


\section{DISCUSSION}

Benin City is a major urban centre in Nigeria. It serves as a busy gateway to the eastern, western and northern parts of the country. The UBTH with its approximately 500-bed space is the largest hospital facility within a radius of over $300 \mathrm{~km}$. It therefore provides trauma service to a large population. The accident and emergency department of this hospital has undergone considerable expansion in recent years so as to cope with the increasing number of trauma patients. The casualty officer assesses in-coming cases and assigns them to the various subspecialties.

Our findings reveal that $28.0 \%$ of RTA patients had facial injuries, which is similar to earlier findings of $20-60 \%$ of RTA victims with some level of maxillofacial injuries. ${ }^{4}$ Varying frequencies of associated injuries in maxillofacial trauma have been reported Posnick et al $33 \%^{8}$, Adekeye $46.7 \%^{9}$, Oji $23 \%{ }^{10}$, Down et al $16 \%{ }^{11}$ and Ugboko et al $81.3 \% .^{2}$ Of the 312 patients with maxillofacial trauma in this study, 138 (44.2\%) had injuries in other parts of the body.

Head injury (55.8\%) accounted for the greater majority of associated injuries, similar to findings from several studies. ${ }^{2,8,9,11}$ Manson $^{1}$ has shown this high incidence of head, maxillofacial and cervical spine injuries in about $75 \%$ of RTA victims. When a forwardmoving vehicle is brought to an abrupt halt, the unrestrained occupants will be thrown upwards and forwards until their movement is arrested by some part of the vehicle, or if they are forcefully ejected from the vehicle on contact with the ground or other objects. The head may come in contact with the windscreen, or with its upper surround and the roof of the vehicle. ${ }^{12}$ The incidence of head injury in this study may have been influenced by the non-enforcement of the seat belt and motorcycle helmet legislation in Nigeria. In the UK where the use of seat belt and motorcycle helmet is mandatory, there has been a reduction in head and maxil- lofacial injuries. ${ }^{13,14}$ The Glasgow coma scale is a useful tool for evaluating head injury patients. ${ }^{15}$

A low incidence of cervical spine injuries was observed in this study. This is unusual, considering the very low utilisation of seat belts and helmets because the incidence of cervical spine injuries is higher when occupants are ejected from their vehicles. ${ }^{16,17}$ However, it has been shown that such injuries can easily be missed during examination..$^{1,11}$ Up to $10 \%$ of patients with facial fractures have a cervical spine injury, and $18 \%$ of those with cervical spine injuries have a maxillofacial injury. ${ }^{5,18}$ Therefore, cervical spine injuries should be considered in all trauma patients especially the unconscious. ${ }^{1}$ Computed tomography (CT) scans are more useful in evaluating cervical spine injuries than plain films, ${ }^{2}$ but financial constraints limit their routine use in our environment.

Orthopaedic injuries are commonly associated with maxillofacial trauma ${ }^{2,8,10,11,19,20}$ and motorcyclists are particularly at risk. ${ }^{12}$ Most often, bones of the lower limb are involved. ${ }^{12,21}$ This is similar to the findings from this study where the combined fractures of the femur, tibia and fibula were predominant.

We did not record any abdominal injuries in our subjects. This is at variance with other reports. ${ }^{2,8,10,11}$ The reason for this is not immediately apparent. While the possibility exists that such injuries may have been missed, it is also possible that such patients may have been assigned to another subspecialty, and despite the presence of a facial injury maxillofacial consultation was not sought for them.

From this study, only 140 (44.85\%) of the patients with maxillofacial injuries were referred to the maxillofacial surgeon. We also observed a delay in the referral of these patients to the maxillofacial surgeon. This ranged from several hours to four weeks. Tanaka et al ${ }^{19}$ observed similar delays. Delay in referral was most often due to head injury. 
The presence of coma should not contraindicate the treatment of a maxillofacial injury. ${ }^{22}$ Deferring treatment of facial injuries makes the aesthetic and functional results substandard. ${ }^{1}$

In conclusion, injuries elsewhere may exist in patients with maxillofacial trauma and, conversely, maxillofacial trauma may coexist with other injuries in a high proportion of cases. This inter-relationship makes it necessary for the maxillofacial surgeon to be part of a multidisciplinary trauma team. This ensures that there are no delays in consultations and referrals and that maxillofacial injuries are managed promptly at the same time as the associated injuries. This is imperative for the best aesthetic and functional results.

\section{ACKNOWLEDGEMENT}

The authors wish to acknowledge the assistance of residents in the Oral and Maxillofacial Surgery Department as well as staff of the Accident and Emergency Department of the UBTH in carrying out this study.

\section{References}

1. Manson PN. Facial injuries. In: McCarthy JG (Ed.). Plastic Surgery. Philadelphia: WB Saunders, 1990, 867-1141.

2. Ugboko VI, Odusanya, SA and Fagade OO. Maxillofacial fractures in a semi-urban Nigeria teaching hospital. A review of 442 cases. Int J Oral Maxillofac Surg 1998; 27: 286-289.

3. Ashar A, Kovacs A, Khan S and Hakim J. Blindness associated with midfacial fractures. J Oral Maxillofac Surg 1998; 56: 1146-50.

4. Huelke DF and Compton CP. Facial injuries in automobile crashes. J Oral Maxillofac Surg 1983; 41: 241-44.

5. Gwyn PP, Carraway JH, Horton CE, Adamson JE and Mladick RA. Facial fractures - associated injuries and complications. Plast Reconstr Surg 1971; 47: 225-230.

6. Christian MS. Non-fatal injuries sustained by seat belt wearers: a comparative study. Br Med J 1976; 2: 1310-13.

7. Posnick JC, Wells M and Pron GE. Paediatric facial fractures. Evolving patterns of treatment. J Oral Maxillofac Surg 1993; 51: 836-844.

8. Chan RN, Ainscow D and Siksorski JM. Diagnostic failures in the multiply injured. J Trauma 1980; 20: 684-687.

9. Adekeye EO. The pattern of fractures of the facial skeleton in Kaduna, Nigeria. Oral Surg Oral Med Oral Pathol 1980; 49: 491-495.

10. Oji C. Jaw fractures in Enugu, Nigeria, 198595. Br J Oral Maxillofac Surg 1999; 37: 106109.

11. Down KE, Boot DA and Gorman DF. Maxillofacial and associated injuries in severely traumatized patients: implications of a regional survey. Int J Oral Maxillofac Surg 1995; 24: 409-412

12. Mant AK. Injuries and death in road traffic accidents. In: Baron DN (Ed.). Pathology of Trauma. London, 1993, 1-16.

13. Rutherford WH, Greenfield T, Hayes HRM and Nelson JK. The medical effects of seat belt legislation in the United Kingdom. Research report No. 13. London: HMSO, 1985.

14. Perkins CS and Layton SA. The aetiology of maxillofacial injuries and the seat belt law. Br J Oral Maxillofac Surg 1988; 26: 353-363.

15. Teasedale G and Bennett B. Assessment of coma and impaired consciousness: a practical scale. Lancet 1974; 1: 81-84.

16. Babcock JL. Cervical spine injuries. Diagnosis and classification. Arch Surg 1976; 111: 646-649.

17. Huelke DF, O’Day J and Mendelsohn RA. Cervical injuries suffered in automobile crashes. J Neurosurg 1981; 54: 316-320.

18. Lewis VL Manson PN, Morgan RF, Cerullo LJ and Meyer PR. Facial injuries associated with cervical fractures: recognition, patterns, and management. J Trauma 1985; 25: 90-95. 
19. Tanaka N, Tomitsuka K, Shionoya K, Andou $\mathrm{H}$, Kimijima Y, Tashiro $\mathrm{T}$ and Amagasa T. Aetiology of maxillofacial fracture. $\mathrm{Br} J$ Oral Maxillofac Surg 1994; 32: 19-23.

20. Bamjee Y, Lownie JF, Cleaton-Jones PE and Lowine MA. Maxillofacial fracture in a group of South Africans under 18 years of age. $\mathrm{Br} \mathrm{J}$ Oral Maxillofac Surg 1996; 334: 298-302.
21. Arotiba GT. Aetiology of facial fractures in Lagos. Nig Postgrad Med J 1996; 3: 37-42.

22. Becker DP, Miller JD, Ward JD, Greenberg RP, Young HF and Sakalas R. The outcome from severe head injury with early diagnosis and intensive management. J Neurosurg 1977; 49: 491-494. 